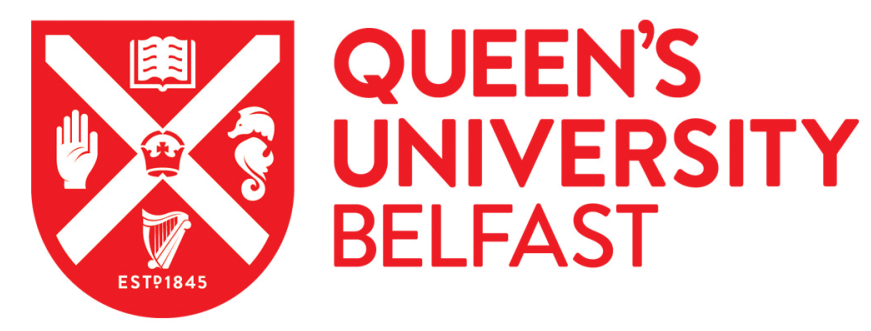

\title{
Effectiveness of family-focused home visiting for maternal mental illness: A systematic review and meta-analysis
}

Leonard, R., Linden, M., \& Grant, A. (2021). Effectiveness of family-focused home visiting for maternal mental illness: A systematic review and meta-analysis. Journal of Psychiatric and Mental Health Nursing. https://doi.org/10.1111/jpm.12715

Published in:

Journal of Psychiatric and Mental Health Nursing

Document Version:

Peer reviewed version

Queen's University Belfast - Research Portal:

Link to publication record in Queen's University Belfast Research Portal

Publisher rights

Copyright 2021 Wiley. This work is made available online in accordance with the publisher's policies. Please refer to any applicable terms of use of the publisher.

\section{General rights}

Copyright for the publications made accessible via the Queen's University Belfast Research Portal is retained by the author(s) and / or other copyright owners and it is a condition of accessing these publications that users recognise and abide by the legal requirements associated with these rights.

Take down policy

The Research Portal is Queen's institutional repository that provides access to Queen's research output. Every effort has been made to ensure that content in the Research Portal does not infringe any person's rights, or applicable UK laws. If you discover content in the Research Portal that you believe breaches copyright or violates any law, please contact openaccess@qub.ac.uk. 
Authors: Rachel Leonard, Mark A Linden, Anne Grant

School of Nursing and Midwifery, Queen's University of Belfast.

\section{Accessible summary}

\section{What is known on the subject?}

- Maternal mental illness reduces a mothers' ability to bond with their infant and may adversely affect other family members.

- Family focused practice is an approach which has the potential to support mothers with mental illnesses and reduce the risk of familial transmission of mental illness to children.

\section{What the paper adds to existing knowledge}

- Findings suggest that current interventions are not effective in reducing depression or stress amongst mothers.

- The majority of interventions included in this review employed relatively low levels of family focused practice.

\section{What are the implications for Practice?}

- While there is a growing integration of family-focused-practice into home visiting guidelines this may be based on poor evidence.

- There is a need for the development of rigorously tested interventions which seek to include the whole family. 


\begin{abstract}
Introduction

The evidence on effectiveness of family-focused home visiting for maternal mental illness has yet to be comprehensively synthesised.
\end{abstract}

\title{
Aim
}

The aim of this study was to assess current home visiting treatments and interventions for mothers with mental illness and their families.

\section{Method}

The primary and secondary outcomes of interest were depression and maternal stress respectively, both were included in meta-analyses. We identified $13(n=5,540$ participants) studies which met inclusion criteria. Eight studies were included in metaanalyses, five studies were reported narratively.

\section{Results}

Findings from the meta-analysis suggest that home visiting interventions are not effective in reducing depression $(\mathrm{SMD}-0.13,95 \% \mathrm{CI}-0.33$ to $0.07, \mathrm{p}=0.21$ ) and maternal stress (MD 0.59, 95\% CI -5.19 to $6.38, \mathrm{p}=0.84)$.

\section{Discussion and Implications for Practice}


Findings suggest that current interventions are not effective in reducing depression or stress amongst mothers. While there is a growing integration of family-focused-practice into home visiting guidelines this may be based on poor evidence.

Keywords: Meta-analysis, Home Visiting, Mental Illness, Family Focused Practice

\section{Introduction}

Maternal mental illness is a major public health issue (Bauer et al. 2014; Hogg, 2013; World Health Organsiation, 2015). Systematic reviews have shown that in highincome countries approximately $10 \%$ of pregnant women, and $13 \%$ of those who have given birth, experience some type of mental disorder, primarily depression or anxiety (Abel, Hope, Swift, Parisi, Ashcroft, Kosidou, Osam, Dalman \& Pierce, 2019; O’Hara $\&$ Swain, 1996). For low- and lower-middle-income countries, those figures increase to $15.6 \%$ in pregnancy and $19.8 \%$ after birth (Fisher et al. 2012). The relationship between maternal mental illness and child health and development outcomes has repeatedly been demonstrated (Herba, Glover, Ramchandani, \& Rondon, 2016; Kingston, Mcdonald, Austin, \& Tough, 2015; Kingston \& Tough, 2014). Research also suggests that these adverse impacts are not limited to children and mothers (Idstad, Ask, \& Tambs, 2010; Iseselo, Kajula, \& Yahya-Malima, 2016): the burden of care on partners and other adult family members is increasingly recognised (Idstad et al. 2010; Iseselo et al. 2016). On this basis, mother's with mental illness and their families are recognised as prime targets for intervention (Reupert, Maybery, \& Kowalenko, 2013; Social Exclusion Task Force, 2007). Findings from systematic reviews support the need for early identification 
and treatment of perinatal mental illness as a potential strategy for preventing the intergenerational transmission of mental illness (Herba et al. 2016; Kingston et al. 2015; Kingston \& Tough, 2014). Public health, early intervention and prevention work is at the core of home visiting (National Institute for Clinical Excellence, 2014). Health visiting in the UK is defined as 'a workforce of specialist community public health nurses (specialised midwives or nurses) who provide expert advice, support and interventions to families with children' (NHS Enlgand, 2014). While the term 'health visitor' is mainly used in the UK, Denmark and Norway, equivalent roles are often referred to as, child health nurses in Sweden, public health nurses in the US, Canada, Ireland and Finland, and child and family health nurses in Australia (Whittaker, 2014). This review will use the term 'home visitor' throughout to acknowledge the variety of terms included in the international literature.

Currently there is one other literature review (Ammerman, Putnam, Bosse, Teeters, \& Van Ginkel, 2010) that explores home visiting and maternal depression, however, this was not a systematic review and the authors neglected to provide any information on their methods resulting in an inability to replicate their findings. Moreover, while the review considered home visiting, it is unclear if they have exclusively examined the home visiting profession, as defined above or included all home visitation professions, such as, social services, family nurse partnership and paraprofessionals. The findings of Ammerman et al., (2010) may therefore not be transferable to home visiting, therefore, this review will be the first to consider FFP and maternal mental health specifically in a population of home visitors.

Due to the negative impact mental illness can have on the whole family, effective interventions should consider the needs of all family members through a 
family focused approach (Diggins, 2011; Foster et al. 2016). Family Focused Practice (FFP), an approach that emphasises the family as the unit of attention (Grant \& Reupert, 2016), improves outcomes for mothers and reduces the burden of care for families while providing a preventative and supportive function for children (Foster, O’Brien, \& Korhonen, 2012; Siegenthaler, Munder, \& Egger, 2012). Hence, all professionals, including psychiatrists and home visitors, are encouraged to consider and address needs of the whole family (Falkov et al. 2015). The term FFP is used interchangeably throughout the literature with terms such as: 'whole family', 'family-oriented', 'familysensitive' and 'family-centred' (Foster et al. 2012; Ward, Reupert, McCormick, Waller, \& Kidd, 2017), consequently there has been a lack of consistency in how the term has been used and defined. For the purposes of this review we have defined FFP as an umbrella term encompassing a continuum of family focused activities, interventions and practices (Grant, 2014; Maybery, Foster, Goodyear, Grant, Tungpunkom, Skogoy, \& Lees, 2015). The majority of research to date has explored FFP in mental health services (Grant \& Reupert, 2016; Maybery, Goodyear, Reupert, \& Grant, 2016; Wong, Wan, \& Ng, 2016), addictions (Hampson, 2013), and social services (Clarke \& Hughes, 2010), however the evidence on the effectiveness of family focused home visiting for maternal mental illness has yet to be comprehensively synthesised. Therefore, our review question sought to determine the effectiveness of current family focused home visiting treatments and interventions for mothers with mental illness.

\section{Methods}

\section{Eligibility Criteria}

Criteria for inclusion in this review consisted of peer-reviewed empirical studies which were family focused, and evaluate home visiting family focused treatments, or 
interventions for maternal mental illness. To determine whether studies were family focused the literature was screened to extract a continuum of family focused activities. These activities were then ranked from low to high based upon previous literature and definitions of FFP. Within the continuum low family focused activities are centred on supporting the individual mother with the aim to have secondary benefits to other family members. For example, the activity of 'directly supporting the mother to parent', supports the mother's parenting skill and capacity, with the aim of having indirect benefits for the child. Whereas activities at the high level not only engage with the family as a whole but view them as a unit of focus. This continuum was then used to determine the extent to which a paper was family focused, and subsequently rate the included studies (see supplementary data). Recognising the relationship between mental illness and substance misuse (Kessler et al. 1996; National Institute on Drug Abuse, 2011), studies that focused on mothers solely with substance misuse, without the coexistence of a mental illness, were included, in addition to studies that focused on mothers with mental illness. As no resources were available for translation, only papers published in English were accepted for review.

Exclusion criteria included review articles, editorials, commentaries, and qualitative research. Since the focus was on home visitors FFP with mother's who have mental illness, studies which exclusively focused on child, adolescent or paternal mental illness were excluded. Studies that employed home-based practice not delivered by home visitors were also excluded (e.g. paraprofessionals, community psychiatric nurses, peer support home visiting or those delivered by religious organisations). As stated previously, home visiting is 'a workforce of specialist community public health nurses (specialised midwives or nurses) who provide expert advice, support and interventions 
to families with children' (NHS Enlgand, 2014, pp. 34). The corresponding author for studies without clearly defined samples were contacted to clarify if home visitors were included.

\section{Search strategy and study selection}

The Preferred Reporting Items for Systematic Reviews and Meta-Analyses (PRISMA) guidelines were used for the conduct and reporting of this systematic review (Moher et al. 2009). Five databases: CINAHL, Medline, PubMed, Web of Science and Maternity and infant care, were systematically searched initially between October and November 2016; which identified 13 papers using a predetermined search strategy. The searches were re-run and the systematic review was updated in April 2019 (re-run searches revealed one new paper). There was no time limit placed on the search strategy. A full list of search terms are outlined in the supplementary data. Screening was conducted independently by two reviewers based on inclusion and exclusion criteria. Where there was uncertainty regarding the eligibility of a particular title or abstract the record was retained for full-text screening $(n=120)$. Following review of the full-texts, fourteen studies were identified for inclusion. A PRISMA flow chart illustrating this process can be found in Figure 1.

\section{[insert figure 1]}

\section{Data extraction}

Data extraction was performed on all eligible studies $(n=24)$, independently by three reviewers using a standardised data extraction template. Disagreements were resolved by discussion between the three reviewers, subsequently leaving 14 studies that were 
deemed to meet the inclusion criteria. Information extracted included: study design, intervention description, participant characteristics, evidence that the intervention was family focused, description of mental illness and/or substance misuse and main findings/data, including means and standard deviations were applicable.

\section{Quality appraisal}

Quality appraisal was conducted on all included studies. Methodological quality was rated independently by the three reviewers. Where disputes arose these were resolved through discussion to reach consensus. The National Institute of Health, quality assessment tool for observational cohort and cross-sectional studies, was used to assess methodological quality of quasi-experimental and observational studies (National Institutes of Health. National Heart Lungs, 2014). Each criterion was given a score of one. When a criterion was regarded as 'unclear' it was given a score of zero.

Randomised Controlled Trials (RCT) were assessed using the Cochrane Collaboration's risk of bias tool which assesses risk of selection, performance, detection, attrition and reporting biases (Higgins et al. 2011). Each area of bias was judged as 'high risk', 'low risk' or 'unclear risk'. Graphical summaries of risk of bias were created using Review Manager software version 5.3 (The Nordic Cochrane Centre, 2014).

\subsubsection{Outcomes}

While the review was primarily interested in any type of maternal mental illness, the majority of the papers considered the mental health outcomes of maternal depression and stress. Prior to conducting the meta-analysis attention was given to outcomes (maternal mental illness) that were comparable between the studies and which featured in enough studies to be able to run the analysis. Subsequently the outcomes of interest 
were depression and maternal stress. Depression was measured by mean overall change (from baseline to end point) of depressive symptoms assessed by any psychometrically validated tool. Examples of these tools included the Edinburgh Postnatal Depression Scale (EPDS) (Cox, Holden, \& Sagovsky, 1987), the General Health Questionnaire (GHQ-28) (Goldberg \& Hillier, 1979), and the Patient Health Questionnaire (PHQ-9) (Kroenke, Spitzer, Williams, Löwe, 2010). In addition, a secondary outcome of parenting stress was included, measured by the Parenting Stress Index - Short Form (PSI-SF) (Abidin, 1995). The three domains included in the PSI-SF are: parental distress, parent-child dysfunctional interaction, and difficult child. The PSI-SF was employed in all studies included in the meta-analysis.

\section{Data analysis and synthesis}

Meta-analysis was conducted where at least three studies reported complete data on outcomes of depression and maternal stress. Data were entered into Review Manager 5.3 for the purposes of conducting meta-analysis. Where data were not reported in full, or was unclear, the corresponding author was contacted and asked to supply additional details. All studies included in the meta-analysis reported continuous data, therefore, the standardised mean difference (SMD) was calculated for outcomes measured using different scales and the mean difference (MD) for outcomes measured on the same scale, with $95 \%$ confidence intervals (CI). A random effects model was applied throughout. Statistical heterogeneity between studies was assessed through visual inspection of forest plots and use of the $\mathrm{I}^{2}$ statistic. One of the nine identified RCT's (Black et al. 1994) did not report on the outcomes of depression or maternal stress, and 
was therefore not included in meta-analyses. For studies $(n=5)$ which did not employ RCT methods, or which failed to report on the outcomes of interest, findings are reported narratively.

\section{Results}

\section{Overview of included studies}

Of the 3,677 papers initially identified, 14 studies published between 1994-2016 were included in the review. These quantitative studies comprised nine Randomised Control Trials (RCT), three quasi-experimental studies, one cohort study and one case series design. The combined total of participants across the 14 studies amounted to 5,940 individuals. The number of participants randomised to the control and intervention groups in the RCTs ranged from 46 to 2,749. A full breakdown of individual sample size and country of origin are detailed in Table 1. Studies varied in their choice of participant group; these included, mothers $(n=9)$, parents (mothers and fathers) $(n=4)$ and relatives $(n=1)$. The primary outcomes of interest also varied and included, depression $(n=7)$, general mental health $(n=5)$ and maternal parenting skills $(n=2)$. Three of the studies used the Structured Clinical Interview for DSM-IV Axis I Disorders to diagnose depression in their sample (Ammerman et al. 2015; Ammerman et al. 2013: Cooper et al., 2015), while the remainder used various scales to measure symptoms of anxiety (e.g. trait anxiety inventory), depression (e.g. Edinburgh Postnatal Depression Scale) or poor mental health (e.g. General Health Questionnaire). Of the two studies (Barlow et al., 2007; Brunette et al., 2004) that considered parenting skills as the primary outcome, general mental health was a secondary outcome. Four trials utilised psychologically informed interventions (i.e. CBT) plus standard care, with the control 
groups receiving standard care (Ammerman et al. 2013, 2015; Horowitz et al. 2013; Morrell et al. 2009). Five studies utilised interventions that were based upon holistic models of practice, such as, integrated family treatment (Brunette, Richardson, White, Bemis, \& Eelkema, 2004), the family nursing model (Thome \& Arnardottir, 2013), family partnership model (Barlow et al. 2007), a preventive model (Cooper, Pascalis, Woolgar, Romaniuk, \& Murray, 2015), a psychoeducational model (Fisher et al. 2016), and an ecological model (Black et al. 1994). Three studies used parenting groups (Long, McCarney, Smyth, Magorrian, \& Dillon, 2001; Patterson et al. 2002; Rowe, McCallum, Le, \& Vittorino, 2012), while the remaining study involved counselling for relatives of drug misusers (Copello, Templeton, Krishnan, Orford, \& Velleman, 2000). All of interventions were commenced postpartum, four of the studies identified mothers antenatally (Morrell et al. 2009; Thome \& Arnardottir, 2013; Barlow et al. 2007; Cooper et al. 2015), while the other identified mothers postnatally.

Interventions employed in the studies were rated using the continuum family focused activities (see supplementary data). Scores on the assessment of the level of family focused practice ranged from 2/34 to 24/34 (See supplementary data). The majority of studies met the criterion of directly supporting the mothers' parenting skills $(n=13)$ and supporting the child via the mother $(n=12)$, which were ranked as low categories of FFP.

[insert table 1]

\section{Quality appraisal}

Quasi-experimental and observational studies. Description of the quality assessment for quasi-experimental and observational studies are reported in Table 2. Three quasi- 
experimental studies failed to include a comparison group (Copello et al. 2000; Long et al. 2001; Thome \& Arnardottir, 2013), however, two employed valid and reliable measures to test pre- and post- differences following intervention (Copello et al. 2000; Thome \& Arnardottir, 2013). One study (Long et al. 2001) used a combination of valid and reliable tools in addition to newly developed measures, of which the latter lacked psychometric assessment. Two studies displayed high dropout rates (Copello et al. 2000; Thome \& Arnardottir, 2013), with Thome and Arnardottir reporting that noncompleters had significantly lower depression scores. All studies used the appropriate statistical methods for analysis. The cohort study (Rowe et al. 2012) employed comparison data, however there were significant demographic differences between the two groups at baseline. While the authors employed valid and reliable measurement tools, the exposure and outcome were not measured in a comparable manner for both groups, Finally, one study involved a case series design, which utilised reliable and valid measurement, with clearly described inclusion criteria (Brunette et al. 2004). However, there was a lack of clear reporting of demographic characteristics.

\section{[insert table 2]}

Randomised controlled trials. The Cochrane Collaboration's risk of bias tool was used to assess selection bias. Graphical assessments of the risk of bias for the included RCT's are reported in Figure 2.

\section{[insert figure 2]}

Selection bias. Five out of the nine RCT's clearly described appropriate methods for random sequence generation, by use of a computer-based random number 
generator (Morrell et al. 2009; Fisher et al. 2016), stratification (Ammerman et al. 2013, 2015) and toss of a coin in the presence of an independent witness (Patterson et al. 2002). The methods of four other RCT's were unclear (Barlow et al. 2007; Black et al. 1994; Cooper et al. 2015; Horowitz et al. 2013). Appropriate methods for allocation concealment were described in five of the RCT's (Ammerman et al. 2013, 2015; Barlow et al. 2007; Cooper et al. 2015; Fisher et al. 2016), whilst the methods of four further RCT's were judged as unclear (Black et al. 1994; Horowitz et al. 2013; Morrell et al. 2009; Patterson et al. 2002). It was deemed that the overall level of selection bias in the RCT's was high.

Performance and detection bias. Blinding of participants and study personnel was assessed as unclear in seven of the nine RCT's, due to non-reporting. Two studies (Morrell et al. 2009; Fisher et al. 2016) clearly described that participants could not be blinded, and that study personnel were blinded prior to allocation. It was determined that while blinding of participants was not possible, this would be unlikely to impact on outcomes, therefore performance bias was assessed as low risk for this study. Outcome assessors were blinded in six of the RCT's (Ammerman et al. 2013; Barlow et al. 2007; Black et al. 1994; Cooper et al. 2015; Fisher et al. 2016; Morrell et al. 2009), while the remaining three studies provided insufficient information to judge the blinding of outcome assessors, and were therefore judged as unclear. It was deemed that the overall level of performance and detection bias in the included RCT's was high.

Attrition bias. Seven (Ammerman et al. 2013, 2015; Barlow et al. 2007; Black et al. 1994; Fisher et al. 2016; Morrell et al. 2009; Patterson et al. 2002) of the nine RCT's attempted to deal with attrition bias by reporting the use of intention to treat (ITT). Five of the studies correctly employed ITT and therefore were deemed at low 
risk of bias. Two studies stated that they employed ITT. However, these had substantial dropout rates (Morrell et al. 2009; Patterson et al. 2002), with one study only retaining $43 \%$ of the intervention group at follow up compared with $82 \%$ of the control group (Patterson et al. 2002). These studies were deemed a high risk of attrition bias. One of the studies failed to include numbers of participants analysed and it was not possible to determine if they truly used ITT, therefore was deemed as unclear risk of bias (Black et al. 1994). Two studies did not use ITT, however, overall attrition across intervention and control was low, therefore attrition bias was deemed as low (Cooper et al. 2015; Horowitz et al. 2013). It was deemed that the overall level of attrition bias in the included RCT's was low.

Reporting bias. Five of the RCT's reported appropriate data for all outcomes reported in their methods, therefore were deemed as possessing low levels of reporting bias (Ammerman et al. 2013; Black et al. 1994; Cooper et al. 2015; Fisher et al. 2016; Patterson et al. 2002). Three studies were deemed at high risk of reporting bias due to lack of reporting outcomes unrelated to this review (Ammerman et al. 2015; Barlow et al. 2007; Horowitz et al. 2013). The remaining study reported their primary outcome using subsets of data, which were not pre-specified, and were therefore deemed as possessing a high risk of reporting bias (Morrell et al. 2009). The overall level of reporting bias in the included RCT's was judged as high.

Other bias. Six of the RCT's were free from any other sources of bias, therefore were deemed as a low risk of other bias. Three studies did not report sufficient information on baseline characteristics of intervention and control groups, therefore it was not possible to determine if there were any significant differences on between groups characteristics (Barlow et al. 2007; Horowitz et al. 2013; Patterson et al. 2002). 
These studies were judged as possessing an unclear risk of other bias. Overall level of other bias was low.

\section{Meta-analysis}

Primary outcome: Depression. Six studies reported on the outcome of depression (Ammerman et al. 2013; Cooper et al. 2015; Fisher et al. 2016; Horowitz et al. 2013; Morrell et al. 2009; Patterson et al. 2002). An overall sample of 2,568 participants were analysed, 1550 receiving home visiting interventions and 1018 receiving standard home visiting or no intervention. As shown in Figure 3, pooled data from the six studies show no statistically significant difference of the interventions on depressive symptoms, as assessed by the EPDS (Cox et al. 1987), the PHQ-9 (Kroenke et al. 2014), and the GHQ-28 (Goldberg \& Hillier, 1979) (SMD = -0.10, 95\% CI -0.26 to $0.07 ; \mathrm{P}=0.24)$. Heterogeneity was moderate $\left(\mathrm{I}^{2}=59 \%\right)$ (Higgins, Thompson, Deeks $\&$ Altman, 2003) and was statistically significant $(P=0.03)$. These results indicate that home visiting interventions did not improve mothers' depressive symptoms.

\section{[Insert figure 3]}

Secondary outcome: Maternal stress. Data on maternal stress was available for four studies (Ammerman et al. 2015; Barlow et al. 2007; Morrell et al. 2009; Patterson et al. 2002), as measured by the PSI-SF. An overall sample of 1,889 participants were analysed, 1,195 receiving home visiting interventions and 694 receiving standard home visiting or no intervention. As shown in Figure 4, following meta-analysis the four studies showed no statistically significant difference $(\mathrm{P}=0.84)$ of 
the interventions on maternal stress, as measured by the PSI-SF (Abidin, 1995). The combined MD for maternal stress $(0.59,95 \% \mathrm{CI}-5.19$ to 6.38$)$ showed an overall increase. Heterogeneity was high $\left(\mathrm{I}^{2}=94 \%\right)$ (Higgins, Thompson, Deeks \& Altman, $2003)$ and was statistically significant $(P=0.000001)$. These results suggest that these home visiting interventions were not successful in improving maternal stress.

\section{[Insert figure 4]}

\section{Narrative summary}

Individual mental illness outcomes. Findings from individual studies report significant improvements of depression and anxiety between baseline and follow up, in three of the studies (Long et al. 2001; Rowe et al. 2012; Thome \& Arnardottir, 2013). Two of the interventions included both mothers and fathers (Long et al. 2001; Thome \& Arnardottir, 2013), however, only 5\% of the sample in one study were men (Long et al. 2001), while the second (Thome \& Arnardottir, 2013) had a high dropout rate of men on follow-up. The third study, purported to include families in their intervention, however, their final sample only included mothers (Rowe et al. 2012). Two of the interventions utilised parenting programmes, based upon a health promotion model (Rowe et al. 2012) and a preventive model of care (Long et al. 2001). Thome and Arnardottir utilised the family nursing intervention (Thome \& Arnardottir, 2013), and reported significant difference of couples depression and state anxiety pre and post intervention ( $\mathrm{P}=0.001)$. A final study (Copello et al. 2000), examining the benefits of an intervention for relatives of drug-users, reported a significant decrease in psychological ill health symptoms $(\mathrm{P}=0.005)$, as measured by The Symptom Rating Test (Kellner, 1986). This study did not include a control group. 
One study reported no change in psychiatric symptoms (Brunette et al. 2004), as measured by the Brief Symptom Inventory (Derogatis \& Melisaratos, 1983). Using an integrated family treatment intervention, the study targeted 'parents' with mental illnesses. However, participants were exclusively female. Black et al., (1994) also reported a non-significant reduction in drug use for women in the intervention group (Black et al. 1994). Despite this, the study did report a significant correlation between the number of home visits and drug-free status $(r=0.53)$.

\section{Discussion}

The primary aim of this study was to answer the question as to whether current family focused home visiting treatments and interventions are effective for reducing maternal mental illness. Findings from the meta-analysis suggest that the home visiting family focused interventions reported here are not effective in improving depression and parenting stress for mothers with mental illness. This is the first meta-analysis evaluating the effects of home visiting family focused interventions on maternal depression and maternal stress.

Out of the six studies included in the meta-analysis for our primary outcome of depression, three utilised interventions that were informed by cognitive behavioural approaches (Ammerman et al. 2013; Horowitz et al. 2013; Morrell et al. 2009), the remaining two studies primarily focused on the mother-infant relationship, one through a preventive model (Cooper et al. 2015), and one through a parenting programme (Patterson et al. 2002). The remaining study was a psychoeducational programme for couples and their babies (Fisher et al., 2016). Five studies scored low on the family 
focused rating, meeting criteria such as 'directly supporting the mothers' parenting skills', 'supporting the mother-infant relationship' and 'supporting the child via the mother'. These criteria are rated as low FFP, as they involve a basic family focused skill set, which is deemed necessary to provide a minimum level of care for all families (Grant \& Reupert, 2016; Reedtz, Lauritzen, \& van Doesum, 2012). One of the studies scored medium on the family focused rating (Fisher et al., 2016), meeting criteria such as "providing psychoeducation to the mother", "providing information to the partner, to support the mother" and "support for partner and family members to help meet their own needs". One of the studies included both mothers and fathers in their sample, however poor reporting of participant characteristics leaves uncertainty as to the proportion of females to males. FFP stipulates that higher levels of practice or interventions must include partners or relevant family members, therefore it is necessary to consider the studies included in this review, inclusion of partners in their interventions and treatments. Findings from the meta-analysis are supported by a previous literature review that also found home visiting to be ineffective for maternal mental illness (Ammerman, Putnam, Bosse, Teeters, \& Van Ginkel, 2010). There are several possible reasons why depressed mothers are unlikely to experience significant symptom reduction as a result of home visiting. These include the lack of specialised mental health training for home visitors and insufficient time to adequately address mental health needs (Ammerman et al. 2010). It is the contention of this review that an additional explanation may include the lack of a family focused approach, which fails to account for the complexity of family dynamics.

A meta-analysis by Dennis and Hodnett found that psychological and psychosocial interventions, the recommended approach for maternal mental illnesses 
(National Institute for Health and Care Excellence, 2014), were effective in improving maternal depression (Dennis \& Hodnett, 2007), however the authors highlighted that little attention was paid to partners and recommended that further research should evaluate interventions that included partners (Dennis \& Hodnett, 2007). The interventions included in their review were delivered by a range of healthcare professionals, with some being delivered by qualified therapists. These are not reflective of the majority of home visiting interventions as qualified therapists may have specialised mental health training, whereas home visitors often possess minimal training.

Three studies, which were not suitable for meta-analysis, reported a significant reduction of depression and anxiety by utilising interventions that were informed by holistic, family focused models (Long et al. 2001; Rowe et al. 2012; Thome \& Arnardottir, 2013). The three studies scored higher on the family focused rating scale, meeting a number of low, medium and high criteria, such as 'providing information to the partner to support the mother (low)', 'engage in separate work with different family members' (medium) and 'assessment of family functioning' (high). Two of the nonRCT studies failed to use a comparison group (Long et al. 2001; Thome \& Arnardottir, 2013), one study (Rowe et al. 2012) did use comparison data, however there were some significant baseline differences between control and intervention groups. Family interventions not specific to home visiting (e.g. family therapy or couples therapy), have also been shown to have a clinically significant impact on the course and impact of mental illness (Falloon, 2003; Garber et al. 2014; Leff et al. 2003). However, to date, home visiting interventions for maternal mental illness have largely remained focused on either the individual mother, or the mother-infant dyad with psychological and 
psychosocial interventions being the recommended intervention for mental illnesses. While there is a growing integration of FFP in home visiting guidelines (National Institute for Health and Care Excellence, 2014) findings from this review suggest this is based on poor evidence. Although findings from individual studies must be interpreted cautiously, preliminary findings from studies employing less robust designs, suggest that FFP may be more effective in reducing maternal depression and anxiety.

In light of the ranges of FFP within the included papers and their variable effectiveness, there are questions as to whether the psychologically based interventions in home visiting would be more effective if delivered with a family focused approach. Thus, there is a need for more rigorous trials of FFP interventions which take a holistic approach to family member inclusion, and consider outcomes for these family members in addition to the mother and child.

\section{Study limitations}

Due to resource limitations it was only possible to include studies published in the English language. It is therefore possible that some of the international literature may have been missed. This could be a contributing factor to the lack of literature from lower income countries. The review concentrated on maternal mental illness, however the majority of the studies focused almost entirely on depression and anxiety, limiting the conclusions that can be made for other mental illnesses. The aim was to include studies which were family focused. To achieve this, a ranking system of family focused activities was developed, drawing on the existing literature and expert knowledge. However, this ranking system has not been empirically tested and therefore its validity is questionable. In addition, it is acknowledged that the criteria of FFP has been applied 
to some studies which have not explicitly stated that they were employing such an approach.

\section{Relevance for clinical practice and research}

The results from meta-analyses show that there is no evidence that home visitor family focused interventions reduce maternal depression or maternal stress. However, findings from individual studies suggest that interventions that scored higher on the FFP rating may be more effective than those that scored lower. It should be noted that these findings are exclusive to depression and anxiety, which are not the only mental illnesses to affect mothers (Fink \& Brock, 2017). Psychological and psychosocial interventions are the widely accepted treatment of maternal mental illness, with the focus of interventions largely alternating between the mother and the mother-infant relationship (Dennis \& Hodnett, 2007; National Institute for Health and Care Excellence, 2014; Tsivos, Calam, Sanders, \& Wittkowski, 2015). However, recognising the impact that mental illness has on both children (Beardslee, Solantaus, Morgan, Gladstone, \& Kowalenko, 2012; Herba et al. 2016; Kingston et al. 2015; Kingston \& Tough, 2014) and partners (Idstad et al. 2010; Iseselo et al. 2016; Ohaeri, 2003), home visiting should take a broader family focused approach. It is recommended that while psychological and psychosocial interventions are widely used, these interventions should be delivered in a family focused manner, specifically, assessing and addressing the needs of the mothers, children, partner and the family unit. Considering the limited evidence that exists in relation to home visitors FFP for mother who have mental illness, it is advisable to firstly conducted mixed methods studies to develop an in-depth understanding. Subsequently, RCT's could be undertaken to examine the impact of FFP for mothers and their families. 


\section{Conclusion}

Further research should utilise rigorous methods to test the effectiveness of home visiting interventions on maternal mental illness. Interventions should adopt a family focused approach to determine whether the inclusion of the family unit impacts on reductions in mental illness. Research is also needed to explore mental illnesses beyond depression, stress and anxiety to improve our understanding of the impact of psychosis, personality disorders or suicidal ideation on maternal and family outcomes. Researchers might seek to use the FFP ranking scale developed in this review to classify the extent of FFP within their own work. This would add to the validity of the scale and provide a standardised approach to assessing FFP.

\section{References}

Abel, K., Hope, H., Swift, E., Parisi, R., Ashcroft, D., Kosidou, K., Osam, C, S., Dalman, C., \& Pierce, M. (2019) Prevalence of maternal mental illness among children and adolescents in the UK between 2005 and 2017: a national retrospective cohort analysis. The Lancet Public Health, 4(6). https://doi.org/10.1016/S2468$\underline{\text { 2667(19)30059-3 }}$ 
Abidin, R. R. (1995). Parenting Stress Index: Professional Manual (Third Edit). Psychological Assessment Resources, Inc.

Ammerman, R., Putnam, F., Bosse, N., Teeters, A., \& Van Ginkel, J. (2010). Maternal Depression in Home Visitation: a Systematic Review. Aggression and Violent Behavior, 15(3), 191-200. doi:10.1016/j.avb.2009.12.002.Maternal

Ammerman, R. T., Altaye, M., Putnam, F. W., Teeters, A. R., Zou, Y., \& Ginkel, J. B. Van. (2015). Depression improvement and Parenting in Low-income mothers in home visiting. Archives of Womens Mental Health, 18(3), 555-563. doi:10.1007/s00737-014-0479-7

Ammerman, R. T., Putnam, F. W., Altaye, M., Stevens, J., Teeters, A. R., \& Ginkel, J. B. Van. (2013). A Clinical Trial of In-Home CBT for Depressed Mothers in Home Visitation. Behavior Therapy, 44(3), 359-372. doi: 10.1016/j.beth.2013.01.002

Barlow, J., Davis, H., McIntosh, E., Jarrett, P., Mockford, C., \& Stewart-Brown, S. (2007). Role of home visiting in improving parenting and health in families at risk of abuse and neglect: results of a multicentre randomised controlled trial and economic evaluation. Archives of Disease in Childhood, 92(3), 229-233. doi:10.1136/adc.2006.095117

Bauer, A., Parsonage, M., Knapp, M., Iemmi, V., Adelaja, B., \& Hogg, S. (2014). The costs of perinatal mental health problems. Centre for Mental Health. Retrieved from https://www.nwcscnsenate.nhs.uk/files/3914/7030/1256/Costs_of_perinatal_mh.pd f.

Beardslee, W. R., Solantaus, T. S., Morgan, B. S., Gladstone, T. R., \& Kowalenko, N. M. 
(2012). Preventive interventions for children of parents with depression: international perspectives. MJA Open, 1(Suppl 1), 23-25. doi:10.5694/mjao11.11289

Black, M. M., Nair, P., Kight, C., Wachtel, R., Roby, P., \& Schuler, M. (1994). Parenting and Early Development among Children of Drug-Abusing Women - Effects of Home Intervention. Pediatrics, 94(4), 440-448. Retrieved from https://www.ncbi.nlm.nih.gov/pubmed/7936850

Brunette, M. F., Richardson, F., White, L., Bemis, G., \& Eelkema, R. E. (2004). Integrated family treatment for parents with severe psychiatric disabilities. Psychiatric Rehabilitation Journal, 28(2), 177-180. doi:10.2975/28.2004.177.180

Clarke, H., \& Hughes, N. (2010). Introduction: Family Minded Policy and Whole Family Practice - Developing a Critical Research Framework. Social Policy and Society, 9(4), 527-531. doi:10.1017/S1474746410000242

Cooper, P. J., Pascalis, L. De, Woolgar, M., Romaniuk, H., \& Murray, L. (2015). Attempting to prevent postnatal depression by targeting the mother-infant relationship: a randomised controlled trial. Primary Health Care Research \& Development, 16(4), 383-397. doi:10.1017/S1463423614000401 [doi]

Copello, A., Templeton, L., Krishnan, M., Orford, J., \& Velleman, R. (2000). A treatment package to improve primary care services for relatives of people with alcohol and drug problems. Addiction Research, 8(5), 471-484. doi:10.3109/16066350009005591

Cox, J. L., Holden, J. M., \& Sagovsky, R. (1987). Detection of postnatal depression . Development of the 10-item Edinburgh Postnatal Depression Scale Detection of 
Postnatal Depression Development of the 10-item Edinburgh Postnatal Depression Scale. British Journal of Psychiatry, 150, 782-786. doi:10.1192/bjp.150.6.782

Dennis, C.-L., \& Hodnett, E. D. (2007). Psychosocial and psychological interventions for treating postpartum depression. Cochrane Database of Systematic Reviews, (4);CD006116. doi:10.1002/14651858.CD006116.pub2

Derogatis, L., \& Melisaratos, N. (1983). The Brief Symptom Inventory: An introductory report. Psychological Medicine, 13(3), 595-605. doi:10.1017/S0033291700048017

Diggins, M. (2011). Think Child, Think Parent, Think Family: A Guide to Parental Mental Health and Child Welfare. SCIE, (December 2011), 1-100. Retrieved from http://www.scie.org.uk/publications/guides/guide30/files/guide30.pdf

Falkov, A., Goodyear, M., Hosman, C. M. H., Biebel, K., Skogøy, B. E., Kowalenko, N., ... Re, E. (2015). A systems approach to enhance global efforts to implement family focused mental health ( MH ) interventions. Child and Youth Services, 37(2), 175-193. doi:10.1080/0145935X.2016.1104104

Falloon, I. R. H. (2003). Family interventions for mental disorders: efficacy and effectiveness. World Psychiatry, 2(1), 20-28. Retrieved from https://www.ncbi.nlm.nih.gov/pmc/articles/PMC1525058/

Brock, C. (2017). Beyond Depression: Anxiety, Psychosis and Other Mental Disorders of Pregnancy and Postpartum. Perinatal Mood Disorders; Parenting Pod (Internet). Retrieved from https://parentingpod.com/depression-anxiety-psychosis-pregnancypostpartum/

Fisher, J., Mello, C. De, Patel, V., Rahman, A., Tran, T., \& Holmes, W. (2012). 
Prevalence and determinants of common perinatal mental disorders in women in low- and lower-middle-income countries : a systematic review. Bulletin of the World Health Organization, 90, 139-149. doi:10.2471/BLT.11.091850

Foster, K., Maybery, D., Reupert, A., Gladstone, B., Grant, A., Ruud, T., ... Kowalenko, N. (2016). Family-focused practice in mental health care: An integrative review. Child \& Youth Services, 37(2), 129-155. doi:10.1080/0145935X.2016.1104048

Foster, K., O’Brien, L., \& Korhonen, T. (2012). Developing resilient children and families when parents have mental illness: A family-focused approach. International Journal of Mental Health Nursing, 21(1), 3-11. doi:10.1111/j.14470349.2011.00754.x

Garber, J., Clarke, G. N., Weersing, V. R., Beardslee, W. R., Brent, D. A., Gladstone, T. R. G., ... Shamseddeen, W. (2014). Prevention of depression in at-risk adolescents: A randomized controlled trial. JAMA Psychiatry, 301(21), 2215-2224. doi:10.1001/jama.2009.788.Prevention

Goldberg, D., \& Hillier, V. (1979). A scaled verison of the General Health Questionnaire. Psychological Medicine, 9, 139-45. doi:10.1017/S0033291700021644

Grant, A. (2014). Registered Psychiatric Nurses' Practice with Parents who have Mental Illness, their Children and Families, within General Adult Mental Health Services in Ireland (Thesis). Melbourne; Faculty of Medicine, Nursing and Health Sciences, Monash University. Retrieved from file://C:/Users/40062706/Downloads/monash_130820.pdf

Grant, A., \& Reupert, A. (2016). The Impact of Organizational Factors and Government Policy on Psychiatric Nurses' Family-Focused Practice With Parents Who Have 
Mental Illness, Their Dependent Children, and Families in Ireland. Journal of Family Nursing, 22(2), 199-223. doi:10.1177/1074840716643770

Hampson, C. (2013). Integrating family-focused practice into routine addiction services (Thesis). Birmingham; School of Psychology, Univeristy of Birmingham. Retrieved from http://etheses.bham.ac.uk/3987/

Herba, C. M., Glover, V., Ramchandani, P. G., \& Rondon, M. B. (2016). Maternal depression 2 Maternal depression and mental health in early childhood: an examination of underlying mechanisms in low-income and middle-income countries. The Lancet Psychiatry, 3(10), 983-992. doi:10.1016/S22150366(16)30148-1

Higgins, J. P., Thompson, S. G., Deeks, J. J., \& Altman, D. G. (2003). Measuring inconsistency in meta-analyses. BMJ (Clinical research ed.), 327(7414), 557-560. https://doi.org/10.1136/bmj.327.7414.557

Higgins, J. P. T., Altman, D. G., Gotzsche, P. C., Juni, P., Moher, D., Oxman, A. D., ... Sterne, J. A. C. (2011). The Cochrane Collaboration's tool for assessing risk of bias in randomised trials. British Medical Journal, 343, d5928-d5928. doi:10.1136/bmj.d5928

Hogg, S. (2013). Prevention in mind: All Babies Count: Spotlight on Perinatal Mental Health. London: NSPCC. Retrieved from https://www.nspcc.org.uk/globalassets/documents/research-reports/all-babiescount-spotlight-perinatal-mental-health.pdf.

Horowitz, J. A., Murphy, C. A., Gregory, K., Wojcik, J., Pulcini, J., \& Solon, L. (2013). Nurse home visits improve maternal/infant interaction and decrease severity of 
postpartum depression. Journal of Obstetric, Gynecologic, and Neonatal Nursing : JOGNN, 42(3), 287-300. doi:10.1111/1552-6909.12038 [doi]

Idstad, M., Ask, H., \& Tambs, K. (2010). Mental disorder and caregiver burden in spouses: the Nord-Trondelag health study. BMC Public Health, 10, 516. doi:10.1186/1471-2458-10-516.

Iseselo, M. K., Kajula, L., \& Yahya-Malima, K. I. (2016). The psychosocial problems of families caring for relatives with mental illnesses and their coping strategies: a qualitative urban based study in Dar es Salaam, Tanzania. BMC Psychiatry, 16(1), 146. doi:10.1186/s12888-016-0857-y

Kellner, R. (1986). The Symptom-Rating Test. In N. Sartorius \& T. A. Ban (Eds.), Assessment of Depression (pp. 213-220). Berlin, Heidelberg: Springer Berlin Heidelberg. doi:10.1007/978-3-642-70486-4_20

Kessler, R. C., Nelson, C. B., McGonagle, K. A., Edlund, M. J., Frank, R. G., \& Leaf, P. J. (1996). The Epidemiology of Co-occuring Addictive and Mental Disorders: Implications for Prevention and Service Utilization. American Journal of Orthopsychiatry, 66(1), 17-31. doi:10.1037/h0080151

Kingston, D., Mcdonald, S., Austin, M., \& Tough, S. (2015). Association between Prenatal and Postnatal Psychological Distress and Toddler Cognitive Development : A Systematic Review. Plos One, 10(5), 1-16. doi:10.1371/journal.pone.0126929

Kingston, D., \& Tough, S. (2014). Prenatal and Postnatal Maternal Mental Health and School-Age Child Development : A Systematic Review. Maternal Child Health Journal, 18, 1728-1741. doi:10.1007/s10995-013-1418-3 
Leff, J., Alexander, B., Asen, E., Brewin, C. R., Dayson, D., Vearnals, S., \& Wolff, G. (2003). Modes of action of family interventions in depression and schizophrenia: The same or different? Journal of Family Therapy, 25(4), 357-370. doi:10.1111/1467-6427.00255

Long, A., McCarney, S., Smyth, G., Magorrian, N., \& Dillon, A. (2001). The effectiveness of parenting programmes facilitated by health visitors. Journal of Advanced Nursing, 34(5), 611-620. doi:10.1046/j.1365-2648.2001.01790.x

Maybery, D., Foster, K., Goodyear, M., Grant, A., Tungpunkom, P., Skogoy, B. E., \& Lees, R. (2015). How can we make the psychiatric workforce more family focused? In Reupert A, Maybery D, Nicholson J, Gopfert M, Seeman MV (2015). Parental Psychiatric Disorder: Distressed Parents and their Families (3 ed., pp. 301-311). Cambridge University Press.

Maybery, D., Goodyear, M., Reupert, A. E., \& Grant, A. (2016). Worker, workplace or families: What influences family focused practices in adult mental health? Journal of Psychiatric and Mental Health Nursing, 23(3-4), 163-171. doi:10.1111/jpm.12294

Moher, D., Liberati, A., Tetzlaff, J., Altman, D. G., Altman, D., Antes, G., ... Tugwell, P. (2009). Preferred reporting items for systematic reviews and meta-analyses: The PRISMA statement. PLoS Medicine, 6(7). doi:10.1371/journal.pmed.1000097

Morrell, C. J., Slade, P., Warner, R., Paley, G., Dixon, S., Walters, S. J., .. Nicholl, J. (2009). Clinical effectiveness of health visitor training in psychologically informed approaches for depression in postnatal women: pragmatic cluster randomised trial in primary care. $B M J, 338$, a3045. doi:10.1136/bmj.a3045 
National Institute for Clinical Excellence. (2014). NICE local government briefing Health visiting, 5, 1-13. Retrieved from https://www.nice.org.uk/advice/lgb22/resources/non-guidance-health-visiting-pdf

National Institute for Health and Care Excellence. (2014). Antenatal and postnatal mental health: clinical management and service guidance. NICE: Clinical guidelines. Retrieved from nice.org.uk/guidance/cg192\%0D

National Institute on Drug Abuse. (2011). Comorbidity: Addiction and Other Mental Illnesses. Retrieved from https://www.drugabuse.gov/publications/drugfacts/comorbidity-addiction-othermental-disorders

National Institutes of Health. National Heart Lungs, and B. I. (2014). Quality Assessment Tool for Observational Cohort and Cross-Sectional Studies. Retrieved from https://www.nhlbi.nih.gov/health-topics/study-quality-assessment-tools

National Health Service Enlgand (2014). National Heath Visiting Core Service Specification. (UK). Retrieved from: https://www.england.nhs.uk/wp-content/uploads/2014/12/hvserv-spec-dec14-fin.pdf.

O’Hara, M. W., \& Swain, A. M. (1996). International Review of Psychiatry Rates and risk of postpartum depression — a meta- analysis Rates and risk of postpartum depression-a. International Review of Psychiatry, 8(1), 37-54. doi:10.3109/09540269609037816

Ohaeri, J. U. (2003). The burden of caregiving in families with a mental illness: a review of 2002. Current Opinion in Psychiatry, 16(4), 457-465. doi:10.1097/01.yco.0000079212.36371.c0 
Patterson, J., Barlow, J., Mockford, C., Klimes, I., Pyper, C., \& Stewart-Brown, S. (2002). Improving mental health through parenting programmes: block randomised controlled trial. Archives of Disease in Childhood, 87(6), 472-477. doi:10.1136/adc.87.6.472

Rathod, S., Pinninti, N., Irfan, M., Gorczynski, P., Gega, L., Rathod, P., \& Naeem, F. (2017). Mental Health Service Provision in Low- and Middle-Income Countries. Health Services Insights, 10(0), 1-7. doi:10.1177/1178632917694350

Reedtz, C., Lauritzen, C., \& van Doesum, K. T. M. (2012). Evaluating workforce developments to support children of mentally ill parents: implementing new interventions in the adult mental healthcare in Northern Norway. BMJ Open, 2(3), e000709-e000709. doi:10.1136/bmjopen-2011-000709

Reupert, A. E., D, J. M., \& Kowalenko, N. M. (2013). Children whose parents have a mental illness: prevalence, need and treatment. Med J Aust, 199(3 Suppl), S7-9. doi:10.5694/mjao11.11200

Rowe, H., McCallum, S., Le, M. T. H., \& Vittorino, R. (2012). Admission to day stay early parenting program is associated with improvements in mental health and infant behaviour: A prospective cohort study. International Journal of Mental Health Systems, 6, 11. doi:10.1186/1752-4458-6-11

Siegenthaler, E., Munder, T., \& Egger, M. (2012). Effect of Preventive Interventions in Mentally Ill Parents on the Mental Health of the Offspring: Systematic Review and. Journal of the American Academy of Child \& Adolescent Psychiatry, 51(1), 8-17.e8. doi:10.1016/j.jaac.2011.10.018

Social Exclusion Task Force. (2007). Reaching out: think family. London, UK: Cabinet Office, 
UK Government. Retrieved from

http://webarchive.nationalarchives.gov.uk/20081023153736/http://www.cabinetoffice.g ov.uk/social_exclusion_task_force/families_at_risk/reaching_out_summary.aspx.

The Cochrane Collaboration (2014). Review Manager (RevMan) [Computer program]. Version 5.3. Copenhagen: The Nordic Cochrane Centre.

Thome, M., \& Arnardottir, S. B. (2013). Evaluation of a family nursing intervention for distressed pregnant women and their partners: a single group before and after study. Journal of Advanced Nursing, 69(4), 805-816. doi:10.1111/j.13652648.2012.06063.x

Tsivos, Z. L., Calam, R., Sanders, M. R., \& Wittkowski, A. (2015). Interventions for postnatal depression assessing the mother/infant relationship and child developmental outcomes: A systematic review. International Journal of Women's Health, 7, 429-447. doi:10.2147/IJWH.S75311

Ward, B., Reupert, A., McCormick, F., Waller, S., \& Kidd, S. (2017). Family-focused practice within a recovery framework: practitioners' qualitative perspectives. $B M C$ Health Services Research, 17(1), 234. doi:10.1186/s12913-017-2146-y

Whittaker, K. (2014). Why Focus on Children: International perspective. In Department of Health event: 0-19 Life course approach to health and wellbeing for children, young people and families (pp. 1-13). Birmingham. Retrieved from https://ihv.org.uk/wp-content/uploads/2014/03/Birmingham-0-19-KarenWhittaker-March-2014-FINAL.pdf.

Wong, O. L., Wan, E. S. F., \& Ng, M. L. T. (2016). Family-centered care in adults' mental health: Challenges in clinical social work practice. Social Work in Mental Health, 
2985(October), 1-20. doi:10.1080/15332985.2015.1038413

World Health Organsiation. (2015). Thinking healthy: A manual for psychosocial management of perinatal depression. Genevea; WHO. Retrieved from http://apps.who.int/iris/bitstream/10665/152936/1/WHO_MSD_MER_15.1_eng.pd f. 4 